JHR

35,2

172

Received 2 September 2019 Revised 23 October 2019 Accepted 28 October 2019

\section{Assessment of healthcare workers' behavior in implementing a newborn screening program for congenital hypothyroidism in Perak, Malaysia}

Hamenudin Hamzah, Rosnah Sutan and Azmi Mohd Tamil Department of Community Health, Universiti Kebangsaan Malaysia Medical Centre, Kuala Lumpur, Malaysia

Aminah Bee Mohd Kassim

Department of Child Health Sector, Family Health Development Division, Ministry of Health Malaysia, Putrajaya, Malaysia

Adliah Mohamed Soid

Department of Perak State Health, Public Health Division, Ministry of Health Malaysia, Putrajaya, Malaysia, and

Amar Singh HSS

Department of Perak State Health, Permaisuri Bainun Hospital, Ministry of Health Malaysia, Putrajaya, Malaysia

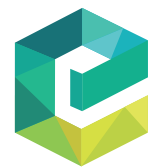

Journal of Health Research Vol. 35 No. 2,2021 pp. $172-185$

Emerald Publishing Limited e-ISSN: 2586-940X p-ISSN: $0857-4421$ DOI 10.1108/JHR-08-2019-0198

\begin{abstract}
Purpose - The aim of this study is to assess healthcare workers' behavior on the congenital hypothyroidism screening program implementation based on a framework protocol and its associated factors.

Design/methodology/approach - A cross-sectional study was conducted using the multistage random sampling method in recruiting health clinic workers and purposive sampling techniques for hospital workers. The demographics, providers' characteristic, occupational profile, attitude, perceived behavior control (PBC), knowledge, behavioral intention and adherence to protocol were gathered using validated and reliable selfadministered questionnaires.

Findings - Partial intention to adhere to protocol was 25.7\%. Weak attitude (adjusted odds ratio [AOR]:5.48, 95\% confidence interval [CI: 3.32-9.06), low PBC score (AOR: 0.91, 95\% CI: 0.86-0.95) and low knowledge score (AOR: $0.85,95 \%$ CI: $0.75-0.96$ ) were associated with partial intention to adhere to protocol. In the self-rated adherence assessment, $92.6 \%$ of participants from health clinics, $79.1 \%$ from pediatric and $61.1 \%$ from pathology were found not adhering to protocol. There was a significant association between intention and adherence to protocol.

Research limitations/implications - Documentations and observations in assessing program implementation were limited to perform in the present study. Using self-rated instruments and focusing on healthcare workers alone did not provide a comprehensive assessment.
\end{abstract}

(C) Hamenudin Hamzah, Rosnah Sutan, Azmi Mohd Tamil, Aminah Bee Mohd Kassim, Adliah Mohamed Soid and Amar Singh HSS. Published in Journal of Health Research. Published by Emerald Publishing Limited. This article is published under the Creative Commons Attribution (CC BY 4.0) license. Anyone may reproduce, distribute, translate and create derivative works of this article (for both commercial and non-commercial purposes), subject to full attribution to the original publication and authors. The full terms of this license may be seen at http://creativecommons.org/licences/by/4.0/legalcode

The authors wish to thank the Perak State Health Department in providing assistance in this study. We would also like to thank the Director-General of Health Malaysia for his permission to publish this article (NMRR-16-2775-33531).

Conflict of interests: There is no conflict of interest.

Funding source: None. 
Practical implications - Availability of a training module at site and regular refreshing course training should be made available to harness knowledge, attitude and behavioral perception in implementing the program activities.

Originality/value - Integrating the Logical Framework Approach in assessing program implementation and application of the Theory of Planned Behavior and Attitude, Subjective Norms, Self-Efficacy Model in this study were beneficial.

Keywords Congenital hypothyroidism, Newborn screening, Malaysia

Paper type Research paper

\section{Introduction}

Congenital hypothyroidism $(\mathrm{CH})$ can be defined as a thyroid hormone deficiency occurring at birth. This causes inadequate thyroxine hormone production and subsequently leads to a child's brain capabilities being less developed [1]. Generally, global statistics have found that the incidence of the disease is estimated as 1 per 2,000-4,000 live births [2-6]. Recent studies have reported that in some countries, the incidence is higher than the global statistics. In Iran for example, rates are estimated to be one in 1000 live births [7, 8]. In China, $\mathrm{CH}$ occurs at one in 2,500 live births [9], and a recent study in India has shown that the incidence of $\mathrm{CH}$ is quite high (1:1000 live births) compared to previous years [10]. As for Malaysia, previous studies have shown that the incidence of $\mathrm{CH}$ occurrence ranges from 1:3,666 to 1:1,170 live births [11-14]. $\mathrm{CH}$ is the most common preventable cause of mental retardation among children [15-17]. Screening for $\mathrm{CH}$ allows early diagnosis and treatment, which in turn can prevent mental retardation, developmental delay and growth restriction. Studies have shown that if the disease is treated early within the first two weeks of life, the child will have a normal or nearly normal intellectual performance by the age of $6-12$ years $[16,17]$. In fact, recent studies among developing countries have found that the $\mathrm{CH}$ screening program is costeffective in most countries [18].

In Malaysia, the $\mathrm{CH}$ screening program has been fully implemented nationwide since 2003 for all newborns in government hospitals [12]. This program aims to ensure that all newborns with $\mathrm{CH}$ can be diagnosed early and treated appropriately to prevent mental disability [1]. Implementation of program activities began with a sample collection until the initiation of treatment and follow-up, which involved the departments of obstetrics, pathology and pediatrics with assistance from health clinics. There are seven predetermined program indicators to monitor program performance. However, the program was reported as not achieving its quality assurance performance in terms of percentage of patients seen for confirmation and percentage of confirmed cases that received treatment within 14 days. Both indicators were set to be $100 \%$. A recent study completed at Sarawak General Hospital achieved up to $94.8 \%$ for the first indicator and $33.3 \%$ for the second indicator [14]. A study conducted in UKM Medical Center a decade ago revealed the same finding [11]. Both studies agreed that the delay can be explained by the turnaround time at three different points. These were laboratory services level (time frame from when the cord blood samples were taken to the time the results were available), clinical service (pediatrics) level (time frame from when the cord blood results were available to the time reviewed by the pediatrics team) and subject level (time taken for a recalled case to return for retesting) [11, 14].

Program performance is influenced by the providers, clients or patients and program support environment. Poor performance at the national level can be due to poor program implementation. A survey carried out among healthcare professionals in Asian countries found that government prioritization, public education and acceptance, cooperation and involvement of healthcare providers are key factors for a successful screening program [19]. It is important to evaluate a healthcare provider's practice in implementing program activities. As far as is known, there are no studies available in terms of assessing the behavior of healthcare providers pertaining to the $\mathrm{CH}$ screening program implementation based on the behavior theories.
Behavior of healthcare workers 
JHR

35,2

174

The Theory of Planned Behavior (TPB) can be applied to understanding the behavior of providers during program implementation. The TPB proposes a model regarding how human action is guided. It predicts the occurrence of specific behavior, provided that the behavior is intentional [20,21]. TPB suggests that the intention of the individual to behave is determined by three main factors, namely, attitude towards behavior, subjective norms and perceived behavior control (PBC) [21]. The model for this theory is illustrated in Figure 1 where the factors mentioned above act as factors in determining behavioral intention, which subsequently affects the individual's actual behavior. Attitude is an individual's favorable or unfavorable feeling towards the behavior. Subjective norms are an individual's estimate of social pressure to perform or not to the target behavior. $\mathrm{PBC}$ is the extent to which a person feels capable of exhibiting such behavior. Several studies have applied this model to the behavior of health professionals, for example, to explore the behavior of doctors' adherence to clinical guidelines [22-26]. There are also studies that specifically assess the behavior of general practitioners in a primary care setting on using general clinical guidelines [27], prescribing and referral behavior [28, 29] and asthma guidelines [30]. Studies among nurses mostly focused on the nurses' intention to implement smoking cessation intervention [31-33], the intention of adherence to clinical guidelines and clinical practices [34-39] as well as health promotion programs $[40,41]$. Two studies among pharmacists were found, focusing on prescription medication [42, 43].

The Attitude, Social Norms, Self-Efficacy (ASE) Model was based on the TPB model and supplemented with elements of the Social Cognitive Theory [21, 44-46]. Apart from the three determinants of behavioral intention, factors such as knowledge, skills and stimuli may play a role. ASE model suggests that individuals with greater knowledge, higher self-efficacy and positive attitude regarding an outcome of behavior are more likely to engage in the behavior as shown in Figure 2. The ASE model with TPB constructs is relevant for behavioral study. These models are widely used in the implementation of research to study the behavioral aspects of the use of guidelines by healthcare professionals [47-51]. The present study used TPB and ASE models to explain the behavior of healthcare providers in implementing newborn screening for $\mathrm{CH}$. The present study aims to assess behavior toward program

Figure 1.

Theory of planned behavior

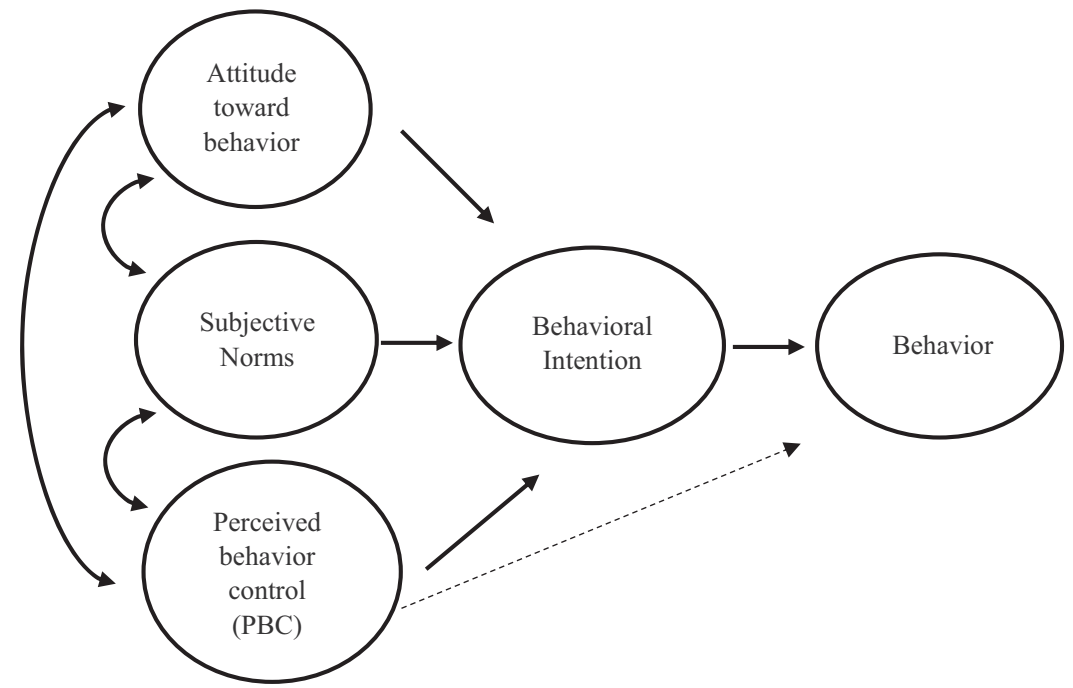

Source(s): Ajzen in 1991 [21] 


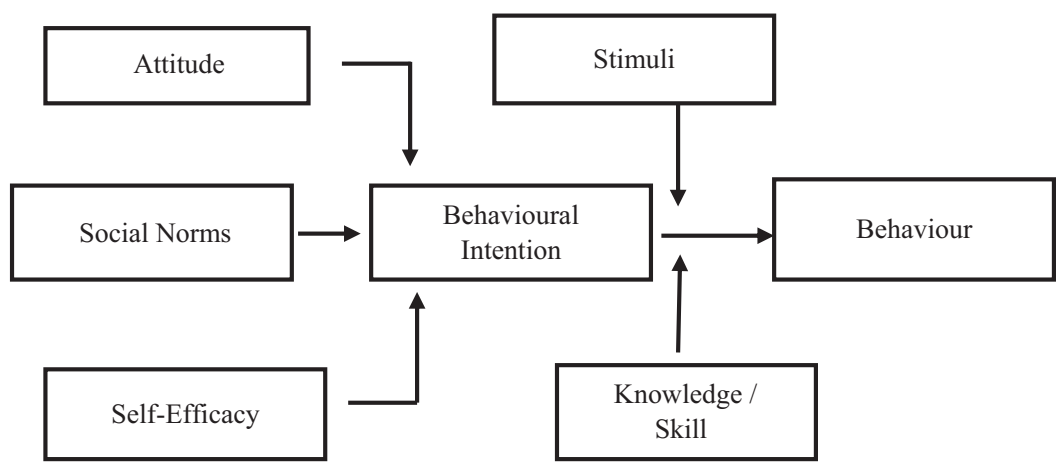

Behavior of healthcare workers

Source(s): De Vries, et al in 1988 [45]

Figure 2.

implementation based on a framework protocol and its associated factors among healthcare workers in government hospitals and health clinics.

\section{Methodology}

Study design and participants

A cross-sectional study was conducted among healthcare workers in 12 government hospitals and 20 health clinics in the Perak state who were involved from receipt of sample stage to the initiation of treatment. It involved healthcare workers in hospitals (pathology and pediatric departments) and health clinics. For pediatrics and health clinics, the participants involved were medical officers and nursing staff, while in the pathology department, science officers and medical laboratory technicians (MLTs) were involved. In order to have enough participants in all of the job categories based on sample size calculation, two sampling methods were applied. Participants from hospitals were selected using the purposive sampling method, whereas the multistage random sampling method was used for the recruitment of health clinic workers. A total of 421 healthcare workers who implemented the program participated in this study.

\section{Instruments and measures}

Research data were gathered using a validated and reliable self-administered questionnaire. It consisted of 75 items and was constructed based on literature reviews [52-55], TPB [21,56] and the ASE Model [44-46]. The questionnaire was developed to assess attitude, PBC, knowledge, behavior intention and adherence to protocol. The reliability test based on Cronbach's alpha ranged from 0.72 to 0.89 . The questionnaire consisted of demographic data, providers' characteristics and the occupational profile of participants. Attitude referred to workers' feelings or opinions toward adherence to the implementation of the program and its importance. The attitude domain consisted of 14 items and ranged from (1) least important to (7) highly important. PBC was defined as the overall evaluation of the degree to which workers believed that a screening program for $\mathrm{CH}$ can be implemented as recommended. It consisted of six items and ranged from (1) strongly disagree to (7) strongly agree. Regarding knowledge, this aspect referred to the score of knowledge items related to the screening program, symptoms and consequences of $\mathrm{CH}$. It consisted of five items assessing knowledge of the screening program, four items on symptoms of the disease and four items on consequences of the disease. Behavioral intention referred to how likely workers intended to adhere to protocol in implementing the program activities. It measured the general intention of workers that led to 
JHR

35,2

adherence. It included four items including compliance to time frame, case management, guideline implementation and cooperation and ranged from (1) least likely to (7) most likely. Adherence to protocol measured compliance to protocol based on the framework protocol of the program. Framework protocol was developed to assist in the implementation of the guideline. It consisted of four main activities in pathology, pediatric and health clinics. There were two items that measured the adherence of each activity in terms of compliance with case management and time frame. In total, there were eight items for each of the facilities and participants provided their answers according to their own workplace.

\section{Ethical consideration}

Approval for this study was obtained from the following: (1) Research and Ethics Committee, Medical Faculty, National University of Malaysia (FF-2017-222, 22 May 2017); (2) Medical Research and Ethics Committee, Ministry of Health Malaysia (NMRR-16-2775-33531 IIR, 14 August 2017); (3) Deputy State Health Director (Public Health) of Perak State; (4) Deputy State Health Director (Medical) of Perak State; (5) respective Hospital Director in Perak State and (6) respective District Health Officer in Perak State.

\section{Data collection}

Data collection was carried out from October to December 2018. A brief description and the purpose of the study were given to the participants. Written consent was taken from participants who agreed to participate. Validated and reliable self-administered questionnaires were then distributed to the participants after agreement was received. All participants had to complete the questionnaires individually and then submit it to the researcher or focal person in the organization on the same day.

\section{Data analysis}

The first part of the analysis included an item analysis section for the full-scale study. Thereafter we analyzed the data to measure intention to adhere and determine its associated factors. Following that, was the analysis of adherence to protocol in order to determine the relationship between intention and adherence to protocol. Data were analyzed by using SPSS, version 21. For descriptive analysis, nominal data were presented as frequency and percentage. All parametric data were presented with mean and standard deviation. Meanwhile, nonparametric data were presented as the median and interquartile range (IQR). For categorical independent variables, the Chi-square test was used. For independent variables presented in continuous data, the independent $t$-test was used if there was a normal distribution. The Mann-Whitney test was used for independent variables that had abnormal distribution. Multiple logistic regression analysis was used to describe the strength of association between outcome and factors of interest, adjustment of covariates or confounders and to determine predictor variables for intention to adhere. A significant level was set at $p<0.05$. However, for bivariate analysis on intention and adherence to protocol according to facilities, a significant value of $p<0.1$ was set for pathology based on the calculated sample size.

\section{Results}

421 healthcare workers participated with a response rate of $93.6 \%$. For the attitude construct, $\mathrm{PBC}$ and behavioral intention, the Cronbach's alpha (CA) was $0.88,0.80$ and 0.98 , respectively. For the knowledge construct, the calculated Difficulty Index was 78.6, which was easy, and the Discriminant Index was 0.36 , which was useful in differentiating those who were knowledgeable and those who were uninformed. This gave the value of Kuder-Richardson at 0.64 , which was reliable. 
Table I, the majority of participants were women (93.6\%) and aged between 24 years and 61 years (mean age: 36 years). Of them, $45.1 \%$ were from health clinics, $42.0 \%$ from pediatrics and $12.8 \%$ from the pathology unit. The prevalence of having a determined attitude was $57.2 \%$ with mean scores for PBC at 34.39. Regarding knowledge, the overall mean score was 10.22. The mean score for knowledge on the screening program, symptoms and consequences of the disease were 4.77, 2.74 and 2.71, respectively. Knowledge of the participants on the screening program was slightly better compared to knowledge on symptoms and consequences of the disease.

\section{Intention to adhere}

In terms of the intention to adhere, most participants $(74.3 \%)$ had shown full intention (Table I). Bivariate analysis showed significant relationships with intention to adhere for training or $\mathrm{CME}(\phi=0.009)$, attitude $(\phi=0.001)$, PBC score $(\phi<0.001)$ and knowledge score $(\phi=0.003)$ as shown in Table II. Multivariate analysis (Table III) showed that a weak attitude (AOR: 5.48, 95\% CI: 3.32-9.06), low PBC score (AOR: 0.91, 95\% CI: 0.86-0.95) and having a low knowledge score (AOR: $0.85,95 \%$ CI: 0.75-0.96) were associated with partial intention to adhere to protocol.

\section{Adherence to protocol}

Table IV, all four activities used to assess adherence in pediatrics showed that more than $25 \%$ did not adhere, and the recall for confirmation test had the highest percentage of nonadherence $(59.3 \%)$. Overall, $20.9 \%$ of participants showed adherence to all four activities (score 4). Thus, $79.1 \%$ of participants were considered as not adhering to the protocol. The

\begin{tabular}{|c|c|c|c|c|}
\hline \multicolumn{2}{|l|}{ Variables } & $n(\%)$ & Mean (SD) & Min, $\max$ \\
\hline \multicolumn{3}{|l|}{ Age (Years) } & $36.49(7.03)$ & 24,61 \\
\hline \multirow[t]{2}{*}{ Gender } & Female & $394(93.6)$ & & \\
\hline & Male & $27(6.4)$ & & \\
\hline \multirow[t]{3}{*}{ Education level } & Degree \& master & $71(16.9)$ & & \\
\hline & Diploma & $240(57.0)$ & & \\
\hline & Certificate & $110(26.1)$ & & \\
\hline \multirow[t]{3}{*}{ Type of facilities } & Health clinic & $190(45.1)$ & & \\
\hline & Pathology & $54(12.8)$ & & \\
\hline & Pediatric & $177(42.0)$ & & \\
\hline \multirow[t]{2}{*}{ Training / CME } & Yes & $130(30.9)$ & & \\
\hline & No & $291(69.1)$ & & \\
\hline \multirow[t]{2}{*}{ Awareness on availability of guideline } & Yes & $373(88.6)$ & & \\
\hline & No & 48 (11.4) & & \\
\hline \multirow[t]{2}{*}{ Used of guideline } & Yes & $351(83.4)$ & & \\
\hline & No & $70(16.6)$ & & \\
\hline \multirow[t]{2}{*}{ Awareness of monitoring by coordinator } & Yes & $318(75.5)$ & & \\
\hline & No & $103(24.5)$ & & \\
\hline \multirow[t]{2}{*}{ Attitude (14 items) } & Strong & $241(57.2)$ & & \\
\hline & Weak & $180(42.8)$ & & \\
\hline \multicolumn{3}{|c|}{ PBC score (6 items) (range score: $6-42$ ) } & $34.39(4.52)$ & 18,42 \\
\hline \multicolumn{3}{|c|}{ Knowledge score (13 items) (range score: $0-13$ ) } & $10.22(1.96)$ & 3,13 \\
\hline \multicolumn{3}{|c|}{ (1) Screening program (5 items) (range score: $0-5$ ) } & $4.77(0.58)$ & 1,5 \\
\hline \multicolumn{3}{|c|}{ (2) Symptoms (4 items) (range score: $0-4$ ) } & $2.74(1.042)$ & 0,4 \\
\hline \multicolumn{3}{|c|}{ (3) Consequences (4 items) (range score: $0-4$ ) } & $2.71(1.065)$ & 0,4 \\
\hline Intention (4 items) & Full & $313(74.3)$ & & \\
\hline & Partial & $108(25.7)$ & & \\
\hline
\end{tabular}

Behavior of healthcare workers 
JHR

35,2

178

\begin{tabular}{|c|c|c|c|c|c|c|}
\hline \multirow[b]{2}{*}{ Variables } & \multicolumn{5}{|c|}{ Intention to adhere } & \multirow{2}{*}{$\begin{array}{c}p- \\
\text { value }\end{array}$} \\
\hline & & Full $(\%)$ & Partial $(\%)$ & $\chi^{2}(\mathrm{df})$ & $t$ & \\
\hline Age (Years)* & & 35.99 (6.562) & $36.66(7.182)$ & & 0.848 & 0.397 \\
\hline Gender & $\begin{array}{l}\text { Female } \\
\text { Male }\end{array}$ & $\begin{array}{r}292(74.1) \\
21(77.8)\end{array}$ & $\begin{array}{r}102(25.9) \\
6(22.2)\end{array}$ & $0.134(1)$ & & 0.715 \\
\hline Education Level & $\begin{array}{l}\text { Diploma \& above } \\
\text { certificate }\end{array}$ & $\begin{array}{r}236(75.9) \\
77(70.0)\end{array}$ & $\begin{array}{l}75(24.1) \\
33(30.0)\end{array}$ & $1.838(1)$ & & 0.175 \\
\hline Type of facilities & $\begin{array}{l}\text { Health clinic } \\
\text { Pathology } \\
\text { Pediatric }\end{array}$ & $\begin{array}{r}144(75.8) \\
39(72.2) \\
130(73.4)\end{array}$ & $\begin{array}{l}46(24.2) \\
15(27.8) \\
47(26.6)\end{array}$ & $0.783(2)$ & & 0.676 \\
\hline Training / CME & $\begin{array}{l}\text { Yes } \\
\text { No }\end{array}$ & $\begin{array}{l}106 \text { (81.5) } \\
207 \text { (71.1) }\end{array}$ & $\begin{array}{l}24(18.5) \\
84(28.9)\end{array}$ & $6.803(1)$ & & 0.009 \\
\hline $\begin{array}{l}\text { Awareness on availability } \\
\text { of guideline }\end{array}$ & $\begin{array}{l}\text { Yes } \\
\text { No }\end{array}$ & $\begin{array}{r}280(75.1) \\
33(68.8)\end{array}$ & $\begin{array}{l}93(24.9) \\
15(31.2)\end{array}$ & $1.060(1)$ & & 0.303 \\
\hline Used of guideline & $\begin{array}{l}\text { Yes } \\
\text { No }\end{array}$ & $\begin{array}{r}263(74.9) \\
50(71.4)\end{array}$ & $\begin{array}{l}88(25.1) \\
20(28.6)\end{array}$ & $0.513(1)$ & & 0.474 \\
\hline $\begin{array}{l}\text { Awareness of monitoring } \\
\text { by coordinator }\end{array}$ & $\begin{array}{l}\text { Yes } \\
\text { No }\end{array}$ & $\begin{array}{r}241(75.8) \\
72(69.9)\end{array}$ & $\begin{array}{l}77(24.2) \\
31(30.1)\end{array}$ & $1.751(1)$ & & 0.186 \\
\hline Attitude & $\begin{array}{l}\text { Strong } \\
\text { Weak }\end{array}$ & $\begin{array}{l}210(87.1) \\
103(57.2)\end{array}$ & $\begin{array}{l}31(12.9) \\
77(42.8)\end{array}$ & $51.7(1)$ & & $<0.001$ \\
\hline $\begin{array}{l}\text { PBC score* } \\
\text { Knowledge score* }\end{array}$ & & $\begin{array}{l}34.93(4.122) \\
10.39(1.946)\end{array}$ & $\begin{array}{r}32.78(5.252) \\
9.73(1.905)\end{array}$ & & $\begin{array}{l}3.825 \\
3.041\end{array}$ & $\begin{array}{r}<0.001 \\
0.003\end{array}$ \\
\hline Note(s): *Independe & & & & & & \\
\hline
\end{tabular}

Table II.

Bivariate analysis between study variables with intention to adhere

Note(s): *Independent $t$-test: Mean (SD)

\begin{tabular}{lcccc}
\hline Variables & $B$ & S.E & AOR & $95 \%$ CI \\
\hline Constant & 3.035 & 1.120 & 20.802 & \\
Attitude & & & & \\
Strong & 1 & & & \\
Weak & 1.701 & 0.256 & 5.480 & $3.32-9.06$ \\
PBC score & -0.100 & 0.027 & 0.905 & $0.86-0.95$ \\
Knowledge score & -0.163 & 0.063 & 0.850 & $0.75-0.96$ \\
Nagelkerk R square & 0.239 & & & \\
Hosmer lemeshow test & 0.070 & & & \\
Overall percentage & 77.2 & & &
\end{tabular}

assessment in pathology showed that the activity of the sample analysis had the highest percentage of nonadherence $(51.9 \%)$. Overall, $38.9 \%$ of participants showed adherence to all four activities (score 4). Thus, $61.1 \%$ of participants were considered to have not adhered to the protocol. As for the health clinics, the activity of referring those who missed the confirmation test had the highest percentage of nonadherence $(61.6 \%)$. Overall, $7.4 \%$ of participants showed adherence to all four activities (score 4). Thus, $92.6 \%$ of participants were considered as not adhering to the protocol. Bivariate analysis (Table IV) showed there were significant relationships between intention to adhere and adherence to protocol for health clinics $(p=0.033)$ and pathology $(\phi=0.077)$ (Table V).

\section{Discussion}

The present study found that a fourth of healthcare workers (25.7\%) partially intended to adhere to protocol of $\mathrm{CH}$ screening implementation. According to the facilities, partial intention was $11.2,10.9$ and $3.6 \%$ for pediatric, health clinics and pathology departments, 


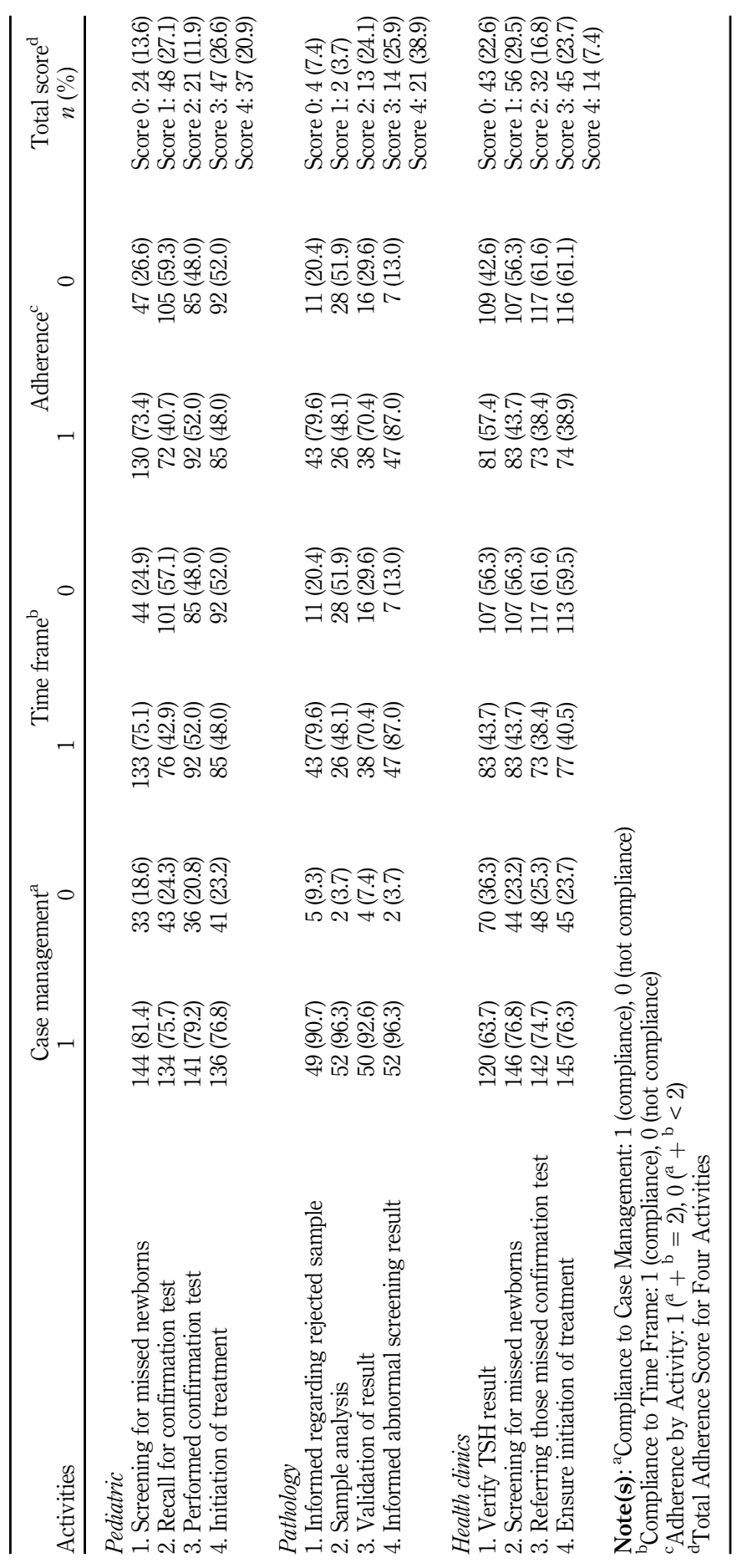

Behavior of healthcare workers

179

Table IV. Pattern of adherence among participants 
JHR

35,2

180

respectively. A higher prevalence of partial intention was documented for both pediatrics and health clinics compared to pathology. This is probably due to the fact that respondents for both pediatric and health clinic departments are doctors and nursing staff as compared to pathology where the respondents comprised science officers and MLTs. In addition to that, the pediatric and health clinic departments had almost identical scopes or roles in this screening program [1]. Specific comparisons could not be drawn as there was no previous study assessing the behavior of healthcare providers in implementing the $\mathrm{CH}$ screening program. Some previous studies, nevertheless, had looked into healthcare professionals' behavior in clinical practices and public health programs based on the TPB and ASE model. In a study conducted by Gagnon et al. [36] among nursing staff to examine their behavior in clinical practices, they found that respondents had a high intention of adherence to the tested clinical practice. Their findings are in tandem with the study conducted by Puffer and Rashidian [39] among British nursing staff. Puffer and Rashidian [39] evaluated the nursing staff's behavior in implementing the guideline of a smoking cessation program and found that $74.5 \%$ of the respondents had a high intention of adherence. Another study conducted on a group of doctors in Florida, USA, aimed to predict their behavior in complying with the clinical practice guidelines that are also consistent with the current research findings [22].

Multivariate analysis demonstrated that the variables in the final model explained that $24 \%$ of the variances in terms of intention to adhere and attitude were found to be the most significant determinant. This finding is in line with the TPB and ASE models in which attitude, PBC towards behavior and the individual's knowledge were factors determining the individual's behavioral intention. There are several other studies that have investigated healthcare professionals' behavior in implementing guidelines. For example, a research study carried out among doctors in Florida to predict their behavior in clinical practice guidelines found that $\mathrm{PBC}$ and attitude were the main determinants with regards to their intention [22]. Other research conducted in Thailand [57], Finland [26], USA [24], Iran [30], England [58, 59], Wales [29] and Canada [28] evaluated doctors' behavior in relation to health and clinical practices and showed similar findings. In contrast, Schellart et al. [60] who investigated Dutch doctors found that there was no significant relationship between attitude and behavioral intention. This is perhaps due to the behavioral intention items that were used. Moreover, the majority of research carried out among nursing staff expounded the extent the TPB model predicted the nurses' behavior. Similar to those studies that examined doctors, most of these studies found that attitude and $\mathrm{PBC}$ toward behavior were the main determinants among nurses.

In terms of adherence to protocol, this research found that percentages of nonadherence were higher among respondents from health clinics $(92.6 \%)$, followed by pediatrics $(79.1 \%)$ and then pathology $(61.1 \%)$. This is similar to the initial hypothesis that formulated a high nonadherence to protocol among health clinic staff compared to hospital staff. As mentioned

Total adherence score

\begin{tabular}{lcccr} 
Intention to adhere & Score $<4(\%)$ & Score $=4(\%)$ & $\chi^{2}(d f)$ & $p$-value \\
\hline $\begin{array}{l}\text { Pediatrics } \\
\text { Partial }\end{array}$ & $39(83)$ & & & $0.583(1)$ \\
Full & $101(77.7)$ & $29(17)$ & & 0.445 \\
Pathology & & & & \\
$\begin{array}{l}\text { Partial } \\
\text { Full }\end{array}$ & $12(80.0)$ & $3(20.0)$ & $3.118(1)$ & 0.077 \\
Health clinics & $21(53.8)$ & $18(46.2)$ & & \\
Partial & & & $4.555(1)$ & 0.033 \\
Full & $44(95.7)$ & $2(4.3)$ & &
\end{tabular}

\section{Table V.}

Bivariate analysis between intention to adhere with adherence to protocol
Partial 
earlier, the prevalence of partial intention to adhere was $25.7 \%$. There was a huge difference compared to the percentage of nonadherence to protocols. There are two possibilities that could explain the difference. First is the method used to measure behavioral intention. In this research, the general behavioral intention method was employed. This method is often used by researchers as it is simpler to implement and does not entail a longer time period and higher costs. Secondly, in evaluating the adherence of respondents, two components were tested, namely compliance of case management and compliance of the time frame for each activity. Four activities were evaluated. Respondents are considered to adhere to protocol if they obtained four adherence scores, which complied with both components for all four activities. This measurement has resulted in a higher percentage of nonadherence and is more prominent compared to the prevalence of partial intention to adhere.

In the present study, the targeted behavior is adherence to the framework protocol. Bivariate analysis revealed that there was a significant relationship between partial intention and adherence to protocol for health clinics and pathology. In implementing appropriate interventions, priority could be given to them. This is consistent with a study conducted by Liabsuetrakul et al. [57] among a group of obstetricians at three major hospitals in Thailand to assess the determinants of intention to use prophylaxis antibiotics during the postcesarean phase. They found that the respondents' behavioral intention was low and attitude was the most distinctive determinant of behavioral intention. Low behavioral intention contributed to the poor use of antibiotics. However, this research finding is different from the research carried out by Maue et al. [22] on a group of doctors in Florida, to predict their behavior in clinical practice guidelines. Although there was a significant relationship between attitude and $\mathrm{PBC}$ of behavioral intention, there was no significant relationship between behavioral intention and self-reported behavior. This was due to the use of a smaller sample size, namely 33 respondents, in the second phase of that research study.

Another important aspect of this research is the suitability of the tool used in measuring behavior. Using a self-reported behavioral measurement is quicker and easier. However, the healthcare system is not keen to change the behavior of self-reported healthcare providers. They are interested in changing the healthcare providers' actual behavior with the hope that this will increase their performance. The main advantage of using theory in the development of instruments to evaluate the behavior of healthcare providers is that outcomes such as intention and self-reported behavior could become a valuable proxy in evaluating actual behavior [61-63]. Behavioral intention is a valid proxy measurement for targeted behavior that could be employed in intervention development. Nevertheless, this depends mainly on the evaluated targeted behavior.

\section{Limitation of study}

In this study, self-rated adherence assessment was used in view of time constraints and budget allocation to make additional observations and documentation assessment. However, the items developed have been validated and were proven reliable. Additionally, this study focused only on healthcare providers without evaluating the perceptions and behavior of the patients. However, this did not affect the study as a basis for evaluating the implementation of the program activities.

\section{Conclusion}

The prevalence of partial intention to adhere to the framework protocol was at $25.7 \%$ with attitude, $\mathrm{PBC}$ and knowledge as the determinants. A high prevalence of nonadherence to the framework protocol was found in all the facilities with a significant association between intention and adherence to the protocol in the health clinics and pathology.

\section{Behavior of healthcare workers}


JHR

35,2

182

\section{Recommendations}

Application of the TPB and ASE Models in assessing the behavior of healthcare providers in this study proved to be beneficial. For this reason, a training module should be made available to focus on improving knowledge, attitude and behavioral perception in implementing the program activities in order to improve program performance.

For future research, it is recommended that involving other Malaysian states using this validated instrument would be beneficial in order to understand the program implementation across Malaysia. To improve the validity of the data, additional observations and documentation assessment would be helpful. Evaluating the perceptions and behavior of the parents of patients is a further recommendation that would provide a more comprehensive assessment.

\section{References}

1. Health Technology Assessment Unit Ministry of Health Malaysia, National screening Programme for congenital hypothyroidism guidelines, Kuala Lumpur, Malaysia: Ministry of Health; 2011.

2. Harris KB, Pass KA. Increase in congenital hypothyroidism in New York State and in the United States. Mol Genet Metab. 2007 Jul; 91(3): 268-77.

3. Hinton CF, Harris KB, Borgfeld L, Drummond-Borg M, Eaton R, Lorey F, et al. Trends in incidence rates of congenital hypothyroidism related to select demographic factors: data from the United States, California, Massachusetts, New York, and Texas. Pediatrics. Pediatrics. 2010 May; 125(Suppl 2): S37-47.

4. Chen CY, Lee KT, Lee CTC, Lai WT, Huang YB. Epidemiology and clinical characteristics of congenital hypothyroidism in an Asian population: a nationwide population-based study. J Epidemiol. 2013; 23(2): 85-94.

5. Barry Y, Bonaldi C, Goulet V, Coutant R, Leger J, Paty AC, et al. Increased incidence of congenital hypothyroidism in France from 1982 to 2012: a nationwide multicenter analysis. Ann Epidemiol. 2016 Feb; 26(2): 100-5.e4.

6. Anastasovska V, Kocova M. Ethnicity and incidence of congenital hypothyroidism in the capital of Macedonia. J Pediatr Endocrinol Metab. 2017 Apr; 30(4): 405-9.

7. Ghasemi M, Hashemipour M, Hovsepian S, Heiydari K, Sajadi A, Hadian R, et al. Prevalence of transient congenital hypothyroidism in central part of Iran. J Res Med Sci. 2013 Aug; 18(8): 699-703.

8. Abedi M, Shahsavari S, Salehi R, Hedayati Nia S, Nasrollahi S, Sadeghi S, et al. The study of prevalence and risk factors of hypothyroidism in newborn screening program in Sanandaj city in 2009 -2014. Zanko J Med Sci. 2015; 15(47): 46-51.

9. Deng K, He C, Zhu J, Liang J, Li X, Xie X, et al. Incidence of congenital hypothyroidism in China: data from the national newborn screening program, 2013-2015. J Pediatr Endocrinol Metab. 2018 Jun; 31(6): 601-8.

10. Chaudhary M, Soni JP, Goyal VK, Sharma P, Makwana M, Lora SS. Incidence of congenital hypothyroidism in Western Rajasthan using cord blood thyroid-stimulating hormone levels as a screening tool: a cross-sectional hospital-based study. Indian J Endocrinol Metab. 2018 May-Jun; 22(3): 417-20.

11. Zarina A, Rahmah R, Bador K, Ng S, Wu LL. Audit of newborn screening programme for congenital hypothyroidism. Med J Malaysia. 2008 Oct; 63(4): 325-8.

12. Singh A. TSH screening of cord blood in Malaysia-its impact (the national congenital hypothyroid screening programme in Malaysian). J Endocrinology and Metabolism. 2010; 1(1): 1.

13. Wong SLJ, Jalaludin MY, Zaini AA, Samingan N, Harun F. Congenital hypothyroidism: an audit and study of different cord blood screening TSH values in a tertiary medical centre in Malaysia. Advances Endocrinol. 2015; (ID 387684): 1-6. 
14. Wong AC, Sue BHL, Gaik CL. Audit of congenital hypothyroidism newborn screening in Sarawak general hospital. Malaysian J of Paediatrics and Child Health. 2017; 20: 38-46.

15. Soliman AT, Azzam S, ElAwwa A, Saleem W, Sabt A. Linear growth and neurodevelopmental outcome of children with congenital hypothyroidism detected by neonatal screening: a controlled study. Indian J Endocrinol Metab. 2012 Jul; 16(4): 565-8.

16. Agrawal P, Philip R, Saran S, Gutch M, Razi M, Agroiya P, et al. Congenital hypothyroidism. Indian J Endocrinol Metab. 2015 Mar-Apr; 19(2): 221-7.

17. Dayal D, Prasad R. Congenital hypothyroidism: current perspectives. Res Rep Endocr Disord. 2015; 5(5): 91-102.

18. Therrell BL Jr, Padilla CD. Newborn screening in the developing countries. Curr Opin Pediatr. 2018 Dec; 30(6): 734-9.

19. Leong YH, Chee Yuen G, Tan MAF, Majid MIA. Present status and future concerns of expanded newborn screening in Malaysia: sustainability, challenges and perspectives. Malays J Med Sci. 2014 Mar; 21(2): 63-7.

20. Ajzen I, Fishbein M. Understanding attitudes and predicting social behaviour. London: PrenticeHall; 1980.

21. Ajzen I. The theory of planned behavior. Organ Behav Hum Decis Process. 1991; 50(2): 179-211.

22. Maue SK, Segal R, Kimberlin CL, Lipowski EE. Predicting physician guideline compliance: an assessment of motivators and perceived barriers. Am J Manag Care. 2004 Jun; 10(6): 383-91.

23. Eccles MP, Hrisos S, Francis J, Kaner EF, Dickinson HO, Beyer F, et al. Do self-reported intentions predict clinicians' behaviour: a systematic review. Implement Sci. 2006 Nov; 1: 28.

24. Askelson NM, Campo S, Lowe JB, Dennis LK, Smith S, Andsager J. Factors related to physicians' willingness to vaccinate girls against HPV: the importance of subjective norms and perceived behavioral control. Women Health. 2010 Mar; 50(2): 144-58.

25. Liang L, Bernhardsson S, Vernooij RW, Armstrong MJ, Bussières A, Brouwers MC, et al. Use of theory to plan or evaluate guideline implementation among physicians: a scoping review. Implement Sci. 2017 Feb; 12(1): 26.

26. Kortteisto T, Kaila M, Komulainen J, Mäntyranta T, Rissanen P. Healthcare professionals' intentions to use clinical guidelines: a survey using the theory of planned behaviour. Implement Sci. 2010 Jun; 5: 51.

27. Carlsen B, Norheim OF. 'What lies beneath it all?'-an interview study of GPs' attitudes to the use of guidelines. BMC Health Serv Res. 2008 Oct; 8: 218.

28. Legare F, Godin G, Ringa V, Dodin S, Turcot L, Norton J. Variation in the psychosocial determinants of the intention to prescribe hormone therapy prior to the release of the Women's Health Initiative trial: a survey of general practitioners and gynaecologists in France and Quebec. BMC Med Inform Decis Mak. 2005 Sep; 5: 31.

29. Webb KL. Theory of planned behaviour: general practitioners' prescribing and referral behaviour. European J for Person Centered Healthcare. 2017; 5(1): 75-81.

30. Rashidian A, Russell I. General practitioners' intentions and prescribing for asthma: using the theory of planned behavior to explain guideline implementation. Int J Prev Med. 2012 Jan; 3(1): 17-28.

31. de Ruijter D, Smit ES, de Vries H, Goossens L, Hoving C. Understanding Dutch practice nurses' adherence to evidence-based smoking cessation guidelines and their needs for web-based adherence support: results from semistructured interviews. BMJ Open. 2017 Mar; 7(3): e014154.

32. Leitlein L, Smit ES, de Vries H, Hoving C. Factors influencing Dutch practice nurses' intention to adopt a new smoking cessation intervention. J Adv Nurs. 2012 Oct; 68(10): 2185-94.

33. Smit ES, de Vries H, Hoving C. Determinants of practice nurses' intention to implement a new smoking cessation intervention: the importance of attitude and innovation characteristics. J Adv Nurs. 2013 Dec; 69(12): 2665-74.
Behavior of healthcare workers 
JHR

35,2

184

34. Côté F, Gagnon J, Houme PK, Abdeljelil AB, Gagnon MP. Using the Theory of Planned Behaviour to predict nurses' intention to integrate research evidence into clinical decision-making. J Adv Nurs. 2012 Oct; 68(10): 2289-98.

35. Cassista J, Payne-Gagnon J, Martel B, Gagnon MP. Applying theory to understand and modify nurse intention to adhere to recommendations regarding the use of filter needles: an intervention mapping approach. Nurs Res Pract. 2014; 2014: 356153.

36. Gagnon MP, Cassista J, Payne-Gagnon J, Martel B. Applying the theory of planned behaviour to understand nurse intention to follow recommendations related to a preventive clinical practice. J Res Nurs. 2015; 20(7): 582-93.

37. Walsh AM, Edwards HE, Courtney MD, Wilson JE, Monaghan SJ. Fever management: paediatric nurses' knowledge, attitudes and influencing factors. J Adv Nurs. 2005 Mar; 49(5): 453-64.

38. Sauls DJ. Nurses' attitudes toward provision of care and related health outcomes. Nurs Res. 2007 Mar-Apr; 56(2): 117-23.

39. Puffer S, Rashidian A. Practice nurses' intentions to use clinical guidelines. J Adv Nurs. 2004 Sep; 47(5): 500-9.

40. Daneault S, Beaudry M, Godin G. Psychosocial determinants of the intention of nurses and dietitians to recommend breastfeeding. Can J Public Health. 2004 Mar-Apr; 95(2): 151-4.

41. Chabot G, Godin G, Gagnon MP. Determinants of the intention of elementary school nurses to adopt a redefined role in health promotion at school. Implement Sci. 2010 Nov; 5:93.

42. Herbert KE, Urmie JM, Newland BA, Farris KB. Prediction of pharmacist intention to provide Medicare medication therapy management services using the theory of planned behavior. Res Social Adm Pharm. 2006 Sep; 2(3): 299-314.

43. Walker A, Watson M, Grimshaw J, Bond C. Applying the theory of planned behaviour to pharmacists' beliefs and intentions about the treatment of vaginal candidiasis with nonprescription medicines. Fam Pract. 2004 Dec; 21(6): 670-6.

44. Bandura A. Social foundations of thought and action. Englewood Cliffs, NJ: Prentice-Hall; 1986.

45. de Vries H, Dijkstra M, Kuhlman P. Self-efficacy: the third factor besides attitude and subjective norm as a predictor of behavioural intentions. Health Educ Res. 1988; 3(3): 273-82.

46. De Vries H, Backbier E, Kok G, Dijkstra M. Measuring the impact of social influences on smoking onset in a longitudinal study: an integration of social psychological approaches. J Appl Soc Psychol. 1995; 25: 237-57.

47. Rebergen D, Hoenen J, Heinemans A, Bruinvels D, Bakker A, van Mechelen W. Adherence to mental health guidelines by Dutch occupational physicians. Occup Med (Lond). 2006 Oct; 56(7): 461-8.

48. Ceccato NE, Ferris LE, Manuel D, Grimshaw JM. Adopting health behavior change theory throughout the clinical practice guideline process. J Contin Educ Health Prof. 2007 Fall; 27(4): 201-7.

49. van Oostrom SH, Anema JR, Terluin B, Venema A, de Vet HC, van Mechelen W. Development of a workplace intervention for sick-listed employees with stress-related mental disorders: intervention Mapping as a useful tool. BMC Health Serv Res. 2007 Aug 15; 7: 127.

50. Brouwer S, Krol B, Reneman MF, Bültmann U, Franche R-L, van der Klink JJ, et al. Behavioral determinants as predictors of return to work after long-term sickness absence: an application of the theory of planned behavior. J Occup Rehabil. 2009 Jun; 19(2): 166-74.

51. Hanbury A, Wallace L, Clark M. Use of a time series design to test effectiveness of a theorybased intervention targeting adherence of health professionals to a clinical guideline. Br J Health Psychol. 2009 Sep; 14(Pt 3): 505-18.

52. Moeller MP, White KR, Shisler L. Primary care physicians' knowledge, attitudes, and practices related to newborn hearing screening. Pediatrics. 2006; 118(4): 1357-70. 
53. Rogha M, Mokhtari E. Study of the knowledge of pediatricians and senior residents relating to the importance of hearing impairment and deafness screening among newborns. Iran J Otorhinolaryngol. 2014 Apr; 26(75): 57-64.

54. Yerraguntla K, Ravi R, Gore S. Knowledge and attitude of pediatric hearing impairment among general physicians and medical interns in coastal Karnataka, India. Indian J Otology. 2016; 22(3): 183.

55. Ravi R, Gunjawate DR, Yerraguntla K, Lewis LE, Rajashekhar B. A national survey of knowledge, attitude and practices among pediatricians towards newborn hearing screening in India. Int J Pediatr Otorhinolaryngol. 2017 Apr; 95:9-14.

56. Francis J, Eccles MP, Johnston M, Walker A, Grimshaw JM, Foy R, et al. Constructing questionnaires based on the theory of planned behaviour: A manual for health services researchers. Newcastle, UK: Centre for Health Services Research, University of Newcastle upon Tyne; 2004.

57. Liabsuetrakul T, Chongsuvivatwong V, Lumbiganon P, Lindmark G. Obstetricians' attitudes, subjective norms, perceived controls, and intentions on antibiotic prophylaxis in caesarean section. Soc Sci Med. 2003 Nov; 57(9): 1665-74.

58. Eccles MP, Hrisos S, Francis JJ, Steen N, Bosch M, Johnston M. Can the collective intentions of individual professionals within healthcare teams predict the team's performance: developing methods and theory. Implement Sci. 2009 May; 4: 24.

59. Hrisos S, Eccles MP, Francis JJ, Bosch M, Dijkstra R, Johnston M, et al. Using psychological theory to understand the clinical management of type 2 diabetes in Primary Care: a comparison across two European countries. BMC Health Serv Res. 2009 Aug; 9: 140.

60. Schellart AJ, Steenbeek R, Mulders HP, Anema JR, Kroneman H, Besseling JJ. Can self-reported disability assessment behaviour of insurance physicians be explained? Applying the ASE model. BMC Publ. Health. 2011 Jul; 11: 576.

61. Bonetti D, Eccles M, Johnston M, Steen N, Grimshaw J, Baker R, et al. Guiding the design and selection of interventions to influence the implementation of evidence-based practice: an experimental simulation of a complex intervention trial. Soc Sci Med. 2005 May; 60(9): 2135-47.

62. Eccles M, Grimshaw J, Walker A, Johnston M, Pitts N. Changing the behavior of healthcare professionals: the use of theory in promoting the uptake of research findings. J Clin Epidemiol. 2005 Feb; 58(2): 107-12.

63. Bhattacharyya O, Reeves S, Garfinkel S, Zwarenstein M. Designing theoretically-informed implementation interventions: fine in theory, but evidence of effectiveness in practice is needed. Implement Sci. 2006 Feb; 1: 5.

\section{Corresponding author}

Rosnah Sutan can be contacted at: rosnah_sutan@yahoo.com

For instructions on how to order reprints of this article, please visit our website:

www.emeraldgrouppublishing.com/licensing/reprints.htm

Or contact us for further details: permissions@emeraldinsight.com 